\title{
Research on the Coupling Relationship between Teaching Style and Classroom Management Based on Grey Correlation Analysis and Multivariate Linear Regression Method
}

\author{
Lihua Yang \\ Dongying Vocational College ,Dongying, China \\ lihua_yang1@163.com
}

\begin{abstract}
Keywords:Variance analysis; Behavior sequence; Gray correlation analysis; Multivariate linear regression; Matching degree; Precise technique
\end{abstract}

\begin{abstract}
With the reform and the deepening of education modernization, the traditional teachercentered classroom management methods can not meet the current needs of teaching, teachers classroom management concept and teaching style occur rapid change with students learning style and personality characteristics, this paper used grey correlative degree analysis and multivariate linear regression method to analyze teaching style and orientation of each dimension of classroom management methods, it is concluded that the matching degree of corresponding characteristics of teachers' teaching style and students can effect teacher's teaching performance and teaching satisfaction and students' learning achievement, and the students' evaluation on the teachers. Through the research it tries to provide theoretical basis and explore ways to education workers in making accurate technique and style to manage the teaching.
\end{abstract}

\section{Introduction}

In the process of the development of teaching activities, according to the teaching objectives and lesson task the classroom management uses management skills, follows specific principles, adopts effective approaches and measures, establishes a good classroom teaching and learning environment to inspire initiative and enthusiasm of students learning and have regulation of efficient completion of teaching activities. For teachers, classroom management is specific pattern of teachers' behavior in the classroom activities, teachers only need to know which side of their performance is more outstanding, and they can choose the appropriate technology and style to have teaching management and effectively establish a rich teaching environment[1]. The correct teaching philosophy and teaching ideas can form a more stable teaching behavior style, and it can directly generate a role of demonstration, guidance to the students, this effects the formation and development of the students' learning behavior. For students, the teaching objectives should be easy to understand, well organized, interlocking, and it also should have layers of analysis, rigorous argumentation, rigorous structure. It uses the power of thinking to attract students' attention and easily control the process of classroom teaching. So that students not only accept the knowledge but also at the same time receive thinking training[2]. Taking a variety of teaching strategies and means has a significant influence of improving the regulation of the teaching style level. Different styles of the alternate usage of teaching strategies make each student have the opportunity to acquire knowledge through their favorite information processing methods and to achieve a purpose of enriching teaching content; it avoids excessive match caused by long-term usage of a style. Therefore only relying on traditional analysis can not see the classroom tasks that need to pay attention and the concern on which aspects of the students and how to focus on them, harmonious development of classroom management has evolved into a single teaching and learning style that both teachers and students can no longer adhere, these problems need to be understood and solved, and they are the important aspects of the teachers' classroom management, the relevance of teaching can be greatly improved only in the way of matching the student's learning style and the teacher's teaching style[3]. Contemporary English teachers should seek comprehensive and a variety of teaching styles that should be flexibly applied to a variety of teaching situations. 


\section{Investigation method of the teaching management strategy}

A.Teaching activities preference TAP

Teaching activities preference TAP (Teaching Activities Preference, referred to as TAP) is evaluation scale of the English teaching activity based on teachers' personality dimensions (cooper, 2010)[4]. The scale divides teaching activities into eight big class teaching styles: extroverted type, introverted type, feeling type, intuition type, thinking type, judgment type, perceptual type and emotion type. This scale is applied for interactive relationship between the students and teachers' teaching, the same personality type of teachers and students will produce good interactive relationship between teachers and students in teaching activities, the teachers with their own cognitive style have preferences for conceptual information processing and logic analysis, pay attention to the training mode of students' logical analysis and objective analysis, so that the students show the openness and flexibility of the idea. Through the stratified random sampling it selected 184 women teachers (accounts for 61.3\% of the sample) and 116 male teachers (accounts for 38.7\% of the sample and their teaching style in different years were investigated, and the results of the survey are shown in Table 1 and Figure 1.

TABLE I.
\begin{tabular}{|c|c|c|c|c|c|c|c|c|}
\hline & $\begin{array}{c}\text { Extroverted } \\
\text { type }\end{array}$ & $\begin{array}{c}\text { Introverted } \\
\text { type }\end{array}$ & $\begin{array}{c}\text { Feeling } \\
\text { type }\end{array}$ & $\begin{array}{c}\text { Intuition } \\
\text { type }\end{array}$ & $\begin{array}{c}\text { Thinking } \\
\text { type }\end{array}$ & $\begin{array}{c}\text { Judgment } \\
\text { type }\end{array}$ & $\begin{array}{c}\text { Perceptual } \\
\text { type }\end{array}$ & $\begin{array}{c}\text { Emotion } \\
\text { type }\end{array}$ \\
\hline $\begin{array}{c}\mathbf{2 0 0 2 -} \\
\mathbf{2 0 1 0}\end{array}$ & 0.62 & 0.38 & 0.79 & 0.21 & 0.62 & 0.38 & 0.59 & 0.41 \\
\hline $\mathbf{2 0 1 1}$ & 0.85 & 0.15 & 0.80 & 0.20 & 0.55 & 0.45 & 0.55 \\
\hline
\end{tabular}

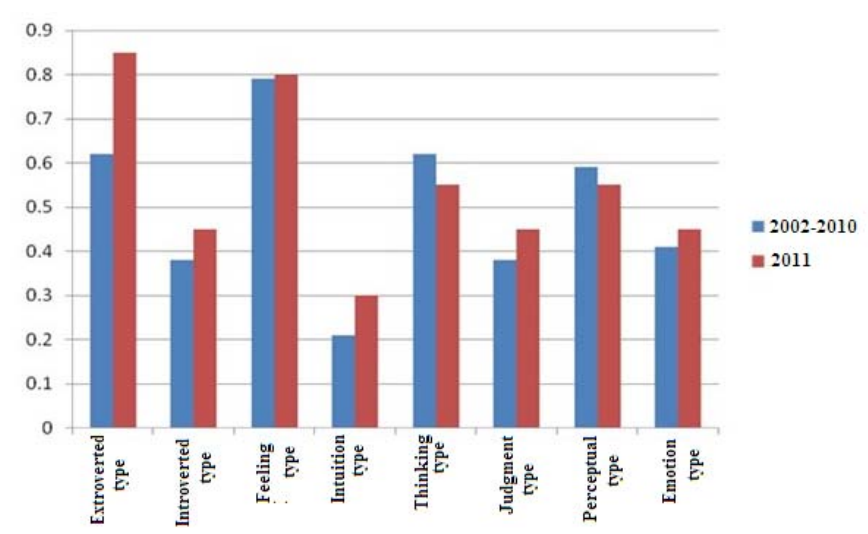

Figure 1. Comparison of distribution chart of test results of different teaching styles

B.Attitude and Beliefs on Classroom Control Inventory ABCC

Attitude and beliefs on classroom control inventory (ABCC) is the questionnaire that designed by Martin and measures the classroom control attitude of teachers. This questionnaire is mainly used for measuring control degree of the teacher in the classroom management. The higher score expresses that your control degree is corresponding higher in class management[5]. According to the research of this scale, it summarizes the strategies and methods of teachers keeping order in their classroom, and the strategies and methods mainly can be divided into three aspects: teaching management, student management and behavior management. Performance strategy of teaching management is the formulation and compliance of rules and procedures, and they include organization of daily work and distribution of materials and so on. As the academic performance evaluation have the characteristics of diversity and timeliness, the students' cognition do not have very big difference, they need to start from the control of classroom management to control the quality of the results. Student management is the training and development management of students' cognitive style based on the acquisition the full trust of students, class assignments and activities is the important one link of students' management. Behavior management contains the feedback information management and interaction, the proper usage of reinforcement and reward mechanism can evaluate the students' behavior and give certain directing management method. 


\section{Choice analysis of teaching style and classroom management orientation based on multivariate linear regression method}

The concept of classroom management can be described through using the three aspects of classroom control attitude beliefs scale, the three aspects are teaching management, student management, and behavior management. The teaching styles mainly have eight categories: extroverted type, introverted type, feeling type, intuition type, thinking type, judgment type, perceptual type and emotion type. From the Table 1 it is known that according to different teachers' teaching style, teaching management part can be represented as the loose management and strict management, and the scores are not the same, the scores are the lowest scores and the highest scores. The higher score presents that the teacher have effective classroom control and intervention method. In the students management section, the lowest score is 8 , the highest score is 32 . The results show that, the teachers often have still intervention and control management. In addition, behavior management is divided into four projects, the lowest score is 4 , the highest score is 16 , but the standard deviation is 2.15, this proves that although the score of the behavior management is not as high as the teaching management and student's management, but behavior management is the most important in the teaching activity.

TABLE II. STATISTICAL TABLES OF EACH PART OF THE CLASSROOM MANAGEMENT BASED ON CLASSROOM CONTROL ATTITUDE BELIEF SCALE

\begin{tabular}{|l|l|l|l|l|l|}
\hline & $\begin{array}{c}\text { The number } \\
\text { of items }\end{array}$ & $\begin{array}{c}\text { Possible } \\
\text { range }\end{array}$ & Score & Standard deviation & $\begin{array}{c}\text { Single } \\
\text { average rate }\end{array}$ \\
\hline Teaching management & 14 & $14-56$ & 44.62 & 5.11 & 3.18 \\
\hline Students management & 8 & $8-32$ & 24.22 & 3.40 & 3.05 \\
\hline Behavior management & 4 & $4-16$ & 11.03 & 2.15 & 2.75 \\
\hline
\end{tabular}

In order to find the relationship between the classroom management and teaching style, it can analyze the correlation matrix. According to the data in Table 3, the positive and important connection exits between the teachers' style and classroom management orientation, the achievement of the teachers that have more control of the classroom discipline and intervention is more obviously than those who have loose management.

TABLE III. CORRELATION MATRICES

\begin{tabular}{|c|l|l|l|l|}
\hline Variables & A & B & C & D \\
\hline Teaching management & 1 & $0.597^{* *}$ & $0.502^{* *}$ & $0.483^{*}$ \\
\hline Students management & 1 & $0.417^{* *}$ & $0.417^{* *}$ \\
\hline Behavior management & & & 1 & $0.407^{* *}$ \\
\hline Teaching style & & & & 1 \\
\hline
\end{tabular}

Therefore, in order to determine the directionality of the influence of differences in teaching style on the classroom discipline, there was a multiple linear regression analysis. Table 3 shows that according to the results of multiple linear regression analysis, the management control of teaching style to the classroom discipline management is in significant level of 0.05 .

\begin{tabular}{|c|l|l|l|l|l|l|l|}
\hline Tource & $\begin{array}{c}\text { Sum of } \\
\text { squares }\end{array}$ & DF & $\begin{array}{c}\text { Square of } \\
\text { mean }\end{array}$ & F & R2 & $\begin{array}{c}\text { Correction of } \\
\text { R2 }\end{array}$ & p \\
\hline Paradigm & 5307.600 & 3 & 1769.200 & 39.631 & 0.287 & 0.000 & \\
\hline Error & 13214.036 & 296 & 44.642 & & & & \\
\hline Collect & 18521.637 & 299 & & & & & \\
\hline
\end{tabular}

According to the results in Table 4, we can know that more than $27 \%$ of the independent variables illustrate the difference influence of teaching style on the classroom management orientation. 
TABLE V. MULTIPLE LINEAR REGRESSION ANALYSIS OF THE CLASSROOM MANAGEMENT

\begin{tabular}{|c|c|c|c|c|}
\hline Variables & $\mathbf{B}$ & $\beta$ & $\mathbf{t}$ & $\mathbf{p}$ \\
\hline Teaching management & 0.442 & 0.287 & 4.401 & 0.000 \\
\hline Students management & 0.381 & 0.165 & 2.651 & 0.008 \\
\hline Behavior management & 0.709 & 0.195 & 3.380 & 0.001 \\
\hline
\end{tabular}

Multiple linear regression formula is[6]: $F=\beta_{0}+\beta_{1} X_{1 i} \beta_{2} X_{2 i}+\beta_{k} X_{k i}+\mu_{i}, \mathrm{i}=1,2, \ldots, \mathrm{n}$;

$\mathrm{t}$ is the number of the explanatory variables, ${ }^{\beta_{j}}(\mathrm{j}=1,2, \ldots, \mathrm{k})$ is called the regression coefficient.

Therefore the result of multiple linear regression analysis on the relevance between the classroom management and teaching style is: when the value is 0.05, the influence of teaching style on the classroom management has a marked impact $(F(1,296)=39.631, P=0.000)$. Thus we can get that predicted value of the reasonable teaching mode should be: value of teaching management is ( $\beta$ $=.287,=4.401)$, value of behavior management is $(\beta=.195,3.380)$ and value of student management is( $\beta=.165,2.651)$.

\section{Factors analysis on teaching style and classroom management orientation based on grey correlation degree}

The factor space that composed of the collections of system factors and the main behavior of system through gray relational subset is the basis of gray correlation analysis, so the comparison and evaluation between the behaviors of the factors is the primary task of the gray relational analysis. $X_{i}=\left(x_{i}(1), x_{i}(2), \cdots x_{i}(n)\right)$ is set to the behavior sequence of related factors of teaching style $X_{i}$, $X_{0}=\left(x_{0}(1), x_{0}(2), \cdots x_{0}(n)\right)$ is set to the behavior sequence of the system characteristics of teaching management, then we can obtain[7,8]:

$$
\begin{array}{ll}
X_{0}=\left(x_{0}(1), x_{0}(2), \cdots x_{0}(n)\right) & X_{1}=\left(x_{1}(1), x_{1}(2), \cdots x_{1}(n)\right) \ldots \\
X_{i}=\left(x_{i}(1), x_{i}(2), \cdots x_{i}(n)\right) & X_{m}=\left(x_{m}(1), x_{m}(2), \cdots x_{m}(n)\right)
\end{array}
$$

They are the related factors sequence of teaching style and classroom management, the real numbers $\gamma\left(x_{0}(k), x_{i}(k)\right)$ are given, if the real numbers $\gamma\left(X_{0}, X_{i}\right)=\frac{1}{n} \sum_{k=1}^{n} \gamma\left(x_{0}(k), x_{i}(k)\right)$ meet the normative, integral and symmetry, then $\gamma\left(X_{0}, X_{i}\right)$ is called the gray correlation degree of $X_{i}$ and $X_{0}$, $\gamma\left(x_{0}(k), x_{i}(k)\right)$ is the correlation coefficient of $X_{i}$ and $X_{0}$ at k point, and $\left|x_{0}(k)-x_{i}(k)\right|$ is smaller, $\gamma\left(x_{0}(k), x_{i}(k)\right)$ is greater.

If each factor of the system factors set can be looked as the point in the space, the observed data of each factor about the different time, different index, different objects is looked as the point coordinate, the relationship between the factors and the characteristics of the system can be studied in the certain n-dimensional space, and it can rely on the distance of n-dimensional space to define the gray relational degree.

The calculation steps of gray relational degree are as follows[9]:

(1) Calculate initial value (or mean value) of each sequence.

$$
X_{i}{ }^{\prime}=X_{i} / x_{i}(1)=\left(x_{i}{ }^{\prime}(1), x_{i}{ }^{\prime}(2) \cdots x_{i}{ }^{\prime}(n)\right), \quad \mathrm{i}=0,1,2, \ldots, \mathrm{m} ;
$$

(2) Calculate differencing sequence.

$$
\Delta_{i}(k)=\left|x_{0}{ }^{\prime}(k)-x_{i}{ }^{\prime}(k)\right|, \quad \Delta_{i}=\left(\Delta_{i}(1), \Delta_{i}(2), \cdots \Delta_{i}(n)\right), \mathrm{i}=1,2, \ldots, \mathrm{m} ;
$$

(3) Calculate the biggest difference and minimum difference of the poles[10]:

$$
M=\max _{i} \max _{k} \Delta_{i}(k) m=\min _{i} \min _{k} \Delta_{i}(k)
$$


(4) Calculate correlation coefficient[11]

(5) Calculate the correlation degree. $\gamma_{0 i}=\frac{1}{n} \sum_{k=1}^{n} \gamma_{0 i}(k), \mathrm{k}=1,2, \ldots \mathrm{m}$.

The data in Table 2 are put into the formula to get the grey correlation results $\gamma_{11}=0.531, \gamma_{21}=0.603, \gamma_{31}=0.624, \gamma_{41}=0.489$.The result is: the relevance of behavior management and teaching style is higher.

\section{Conclusion}

The study shows that the styles of teaching match with the materials, content and performance of the learning, then learners will find that the learning task is relatively easy, but the case of false matches, through the development of the learning of materials that do not match with learners' cognitive style, the efficiency of learning and interest of the learner will greatly reduce. This paper shows that the teacher's teaching style and teaching and learning process of classroom management have the interaction and mutual influence. This interaction and impact in the English teaching activities has more complex and more levels. because of the working content of the English teachers not only simply passes the teaching content to the students, but also needs to think about how to put their own teaching style and charismatic personality into classroom management to make students master the application ability of the language in practice. Only achieve the harmonious development of the teaching style and student learning styles it can promote the diversification forward of the student learning style, and it has important practical significance of the optimization of the process of teaching and improving the quality of the English classroom practice. Most of the previous working were trying to move the traditional old-line teaching mode to the classroom, teacher and the thinking of the students did not get rid of the traditional mode, this paper according to the new network environment and a variety of research had a integration of the personalized style of teachers and teaching event management to promote the transformation of new teaching methods, establish new teaching theoretical framework, propose new teaching methods, more accurate technology, develop the English personalized learning and provide more scientific basis for the establishment of a new classroom management model.

\section{References}

[1] Cheng Wei, Han Anzhuang. Effective relationship of junior high school teachers' classroom management methods and their teaching behavior .Binzhou University 2007, 23 (1):49-51

[2] Liu Jiafang, Liu Chengfang. Classroom management behavior orientation.Southwest university for nationalities journal (Humanities and Social Science) 2010, 25 (9):113-115

[3] Liu Sifeng,Fang Zhigeng. Theory and application of gray system , Science Press, 2010:26-28

[4] Cao Yanhua,Wu Xihong. Personalized teaching cognitive style model with measurement.Exploration and Practice, 2011, 12 (3):56-59

[5] Peng Jinlan. Interactive orientation of the English classroom teaching.Central China Normal University Press, 2011(10):13-16

[6] Liu Daoyi. English education essays.Beijing Foreign Languages Press, 2011:212-219.

[7] XiaohuLi.English curriculum standards. People Education Press, 2003,4

[8] Xu Qi. Explore of the identity of middle school foreign language teachers.Era education. 2010 (9):71-73

[9] Chang Sheng, Zhu Yaling. Studies of multiple linear regression of the algorithm modeling based on SPSS .China paper Center, 2007:455-467.

[10] Mehrak Rahimi, Fatameh Hosseini K. EFL teachers 'classroom discipline strategies: the students' perspective.Procedia - Social and Behavioral Sciences,2012. 309-314

[11] Fatemeh Asadollahi. EFL teachers' classroom management orientations: investigating the role of individual differences and contextual variables. Procedia - Social and Behavioral Sciences,2012:43-48 